\title{
A call to action: exercise as treatment for patients with mental illness
}

\author{
Robert Stanton $^{\mathrm{A}, \mathrm{F}}$, Simon Rosenbaum ${ }^{\mathrm{B}, \mathrm{C}}$, Megan Kalucy ${ }^{\mathrm{C}, \mathrm{D}}$, Peter Reaburn ${ }^{\mathrm{E}}$ \\ and Brenda Happell ${ }^{\mathrm{A}}$ \\ ${ }^{A}$ Centre for Mental Health Nursing Innovation, Institute for Health and Social Science Research, \\ School of Nursing and Midwifery, Central Queensland University, Bruce Highway, \\ North Rockhampton, Qld 4702, Australia. \\ ${ }^{B}$ The George Institute for Global Health and School of Public Health, University of Sydney, 321 Kent Street, \\ Sydney, NSW 2000, Australia. \\ ${ }^{\mathrm{C}}$ School of Psychiatry, University of New South Wales, Randwick, NSW 2031, Australia. \\ DSouth Eastern Sydney and Illawarra Health Service, Bondi Junction Community Health Centre, \\ 26 Llandaff Street, Bondi Junction, NSW 2022, Australia. \\ ${ }^{E}$ School of Medical and Applied Sciences, Central Queensland University, Bruce Highway, \\ North Rockhampton, Qld 4702, Australia. \\ FCorresponding author. Email: r.stanton@cqu.edu.au
}

\begin{abstract}
Mental illness affects the lives of a significant number of Australians. In addition to pharmacological and psychological interventions, exercise has demonstrated benefits for people with mental illness including symptom reduction, improved cardiovascular risk profile and improved physical capacity. Unfortunately, evidence shows that clinician-delivered exercise advice is not routinely offered. This is despite patient acceptability for exercise. This article summarises the recent evidence supporting the prescription of exercise for people with mental illness and offers a model incorporating basic exercise prescription, and referral pathways for specialised advice. Current exercise prescription patterns for people with mental illness may not meet patient expectations; therefore, clinicians should consider exercise referral schemes to increase the accessibility of interventions for people with a mental illness.
\end{abstract}

Received 21 March 2014, accepted 1 July 2014, published online 18 July 2014

\section{Introduction}

Approximately 7.3 million Australians will be affected by mental illness during their lifetime (AIHW 2013). The Institute of Health and Welfare estimates some 15 million, or more than $12 \%$ of GP encounters, are mental health-related, with more than 2 million Medicare-subsidised mental health services provided by Australian GPs in 2011-2012 (Britt et al. 2012). The economic cost of mental illness is significant, with costs to the Australian health-care system approaching A\$7 billion (AIHW 2013) or $\sim 0.4 \%$ of Gross Domestic Product, while the contribution of mental illness to lost productively in the Australian workforce approaches A \$6 billion (Hilton et al. 2010).

There appears to be a strong reliance on pharmacotherapy as the first-line treatment strategy for some mental illnesses. For example, a survey of Victorian GPs (McGarry et al. 2005) reported that more than $80 \%$ prescribed medication to patients with depression. This trend in prescribing rates of psychotropic medication is consistent with cross-sectional analysis of Pharmaceutical Benefits Scheme (PBS) data showing a 95\% increase in antidepressant medication prescriptions between 2001 and 2011 (Stephenson et al. 2013).
Australian clinical practice guidelines for the treatment of some mental illnesses, including schizophrenia and related disorders (McGorry et al. 2005) and depression (Ellis 2004), advocate for the inclusion of physical activity or exercise. However, these guidelines do not include recommendations on the frequency, intensity, time (duration) or type of exercise intervention (FITT). These parameters, in addition to the level of supervision and delivery mode, may be critical to ensuring positive outcomes for people with mental illness. In contrast, despite some evidence for the effectiveness of exercise to manage overweight and obesity in people with bipolar disorder (Elmslie et al. 2001), the most recent Australian guidelines for the management of bipolar disorder (Royal Australian and New Zealand College of Psychiatrists Clinical Practice Guidelines Team for Bipolar Disorder 2004) make no mention of the potential therapeutic benefits of exercise.

\section{Evidence for exercise}

There is little doubt that pharmacotherapy or psychotherapy is necessary and beneficial for some patients with mental illness. However, there is growing evidence that exercise may play a 


\section{What is known about the topic?}

- Evidence exists for the benefits of exercise for people with mental illness, yet the exercise prescribing rate by GPs is alarmingly low.

\section{What does this paper add?}

- We show that patients consider exercise to be a highly regarded treatment option and suggest the use of referral schemes to increase the uptake of exercise by mental health consumers.

valuable role in the treatment (Cooney et al. 2013; Malchow et al. 2013) and prevention (Mammen and Faulkner 2013) of some mental illnesses. For example, Cochrane reviews on exercise and mental illness have confirmed the effectiveness of exercise in the treatment of both depression (Cooney et al. 2013) and schizophrenia (Gorczynski and Faulkner 2010). Furthermore, a recent systematic review of the effects of exercise on anxiety disorders (Jayakody et al. 2014) concluded that exercise may be effective as a complimentary therapy but less effective compared with traditional pharmacotherapy. Studies also show therapeutic benefits of exercise for other mental illnesses including panic disorder (Wolff et al. 2011) and obsessive compulsive disorder (Brown et al. 2007; Abrantes et al. 2009).

Patients with mental illness are also more likely to be overweight and have higher rates of cardiometabolic disease compared with the general population (Galletly et al. 2012). Evidence suggests exercise may reduce cardiometabolic symptoms in patients with mental illness (Caemmerer et al. 2012) with few adverse events (Rimer et al. 2012) and with exercise adherence rates similar to those observed in the general population (Stanton and Reaburn 2014).

While there are some limitations with the generalisability of the findings of some systematic reviews and meta-analysis, evidence for the efficacy and acceptability of exercise in the treatment of mental illness is mounting. Specific information is lacking when it comes to providing exercise prescription recommendations based on the FITT principle (Morgan et al. 2013a); however, a recent review (Stanton and Reaburn 2014) suggested that the exercise parameters likely to lead to positive outcomes for people with depression are not markedly different to those recommended for the general population (Table 1). In particular, the availability of both group and individual activities to which patients may be directed, based on patient preference and accessibility, are likely have similar effectiveness.

\section{GP exercise prescribing rates}

Despite the above evidence highlighting the effectiveness of exercise for people with mental illness, little is known about the exercise prescribing habits of Australian GPs for this clinical population. An early study (McGarry et al. 2005) reported that approximately three-quarters of GPs surveyed prescribed exercise to only $50 \%$ of their patients with depression. A more recent study (Robertson et al. 2011) reported that mental illness accounted for only $7 \%$ of all conditions for which exercise was

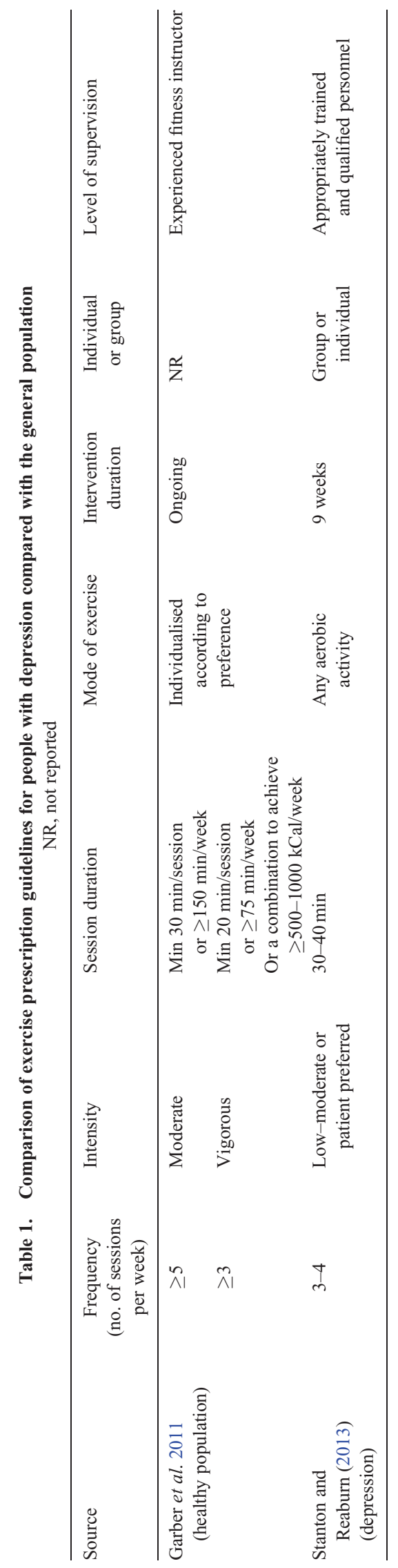


prescribed by GPs. Lastly, data from the 'Bettering the Evaluation of Health and Care' initiative (BEACH) suggest that Australian GPs provide exercise counselling at a rate of 1.3/100 encounters (Britt et al. 2012). Regardless of the evidence for the efficacy of exercise as either a first-line or adjunct treatment for people with mental illnesses, and, despite GPs rating becoming more physically active above other therapeutic activities (Morgan et al. 2013b), the rates of GP prescribed exercise remains low. The reasons for this are not fully understood. Some (Abramson et al. 2000; Livaudais et al. 2005; Toosi et al. 2009), but not all (Frank et al. 2000; Rogers et al. 2006) international studies report that physicians who engage in higher levels of exercise themselves are more likely to provide exercise counselling to patients. However, a recent systematic review concluded that, in general, lack of time and lack of knowledge are significant barriers to exercise counselling by physicians (Hébert et al. 2012).

If these factors are representative of the barriers to exercise prescription by Australian GPs, then the use of incentive-based referral schemes such as the Medicare Enhanced Primary Care scheme, for specialist care in lifestyle management including exercise, would seem a prudent inclusion in holistic patient care.

\section{Exercise referrals}

Accredited exercise physiologists (AEPs) are arguably the most relevant allied health professional for Australian GPs and other clinicians to refer patients with mental illness to for exercise guidance. AEPs undergo rigorous clinical training and supervision across several fields including mental health. AEPs are becoming more frequently employed in mental health services including Queensland Health and Monash Health. Approximately one-third of nurses working in mental health report discussing the physical health of mental health consumers with AEPs (Happell et al. 2014). The peak body for AEPs, Exercise and Sports Science Australia, recently released a review on exercise and mental illness, and several AEPs who are researchers in the field of exercise and mental illness have made significant contributions to the academic and applied knowledge in the field (e.g. Rosenbaum et al. 2011, 2014; Stanton and Happell 2014; Stanton and Reaburn 2014; Stanton et al. $2014 a, 2014 b$ ). However, despite evidence of the effectiveness of referral schemes for people with mental illness (Forsyth et al. 2009), a recent survey reported that $\sim 40 \%$ of AEPs have never received a GP referral for patients with a mental illness (Stanton 2013).

This contrasts markedly with the use of exercise referral schemes in the UK where $\sim 80 \%$ of GPs who have access to exercise referral schemes utilise the resource in the treatment of patients with depression (Mental Health Foundation 2009). However, despite the high use of exercise referral schemes in the UK, the uptake of such schemes by patients is variable due to social and motivational constraints (Donaghy and Taylor 2010).

\section{Patient perspective}

With patients becoming increasingly well informed, there is a need to consider their knowledge and expectations regarding treatment options. For example, Berk et al. (2013) recently reported that people with depression view exercise as a highly regarded yet underutilised self-management strategy. Moreover, recent evidence points to the acceptability of GP-prescribed exercise by patients with mild to moderate depression (Searle et al. 2011). However, it needs to be recognised that people with a mental illness may present with significant barriers to the uptake of exercise including low motivation, lack of enjoyment and persistent fatigue (McDevitt et al. 2006; Carpiniello et al. 2013). In addition to low motivation and comorbid health conditions, Glover et al. (2013) reported people with a mental illness specifically identify medication side-effects and conditionrelated symptoms as significant barriers to participation in regular exercise. Use of the available referral schemes may help bridge the gap between growing patient expectations and the actions of GPs.

\section{Evidence exercise works: mechanisms of action}

The mechanisms explaining the benefits of exercise for people with mental illness are not fully understood. However, one mechanism proposed to explain the mood enhancing effect of exercise involves an increase in brain-derived neurotrophic factor (BDNF) that leads to increased neuronal survival (Lipsky and Marini 2007). As BDNF is also a powerful modulator of several neurotransmitters, this may reduce stress reactivity, thus leading to a reduction in allostatic load (Crews and Landers 1987). Exercise may also directly influence allostatic load by decreasing sympathetic nervous system and hypothalamic-pituitaryadrenal axis activity (Tsatsoulis and Fountoulakis 2006). The resultant reduction of allostatic load via indirect and direct mechanisms leads to enhanced neuronal plasticity and stress tolerance. This potential mechanism of action is not dissimilar to that of antidepressant medication. A detailed review of these pathways is examined in Sylvia et al. (2010) and Helmich et al. (2010).

A second potential mechanism is through psychological means. Several recent reviews have alluded to the befits of exercise in reducing anxiety sensitivity, providing distraction to ruminating thoughts, improved body image changes, social reinforcement, experience of mastery, shift of external to more internal locus of control, and improved coping strategies (Stathopoulou et al. 2006; Asmundson et al. 2013; Zschucke et al. 2013).

\section{Practice implications}

Evidence is mounting for the efficacy and acceptability of GP-prescribed exercise for patients with mental illness. The recent research evidence strongly suggests a similarity in terms of exercise recommendations to that of other clinical populations or the general population. However, the rates of exercise prescription by GPs or the use of referral schemes for individualised exercise advice for patients with mental illness is generally low. General practitioners should be aware that the benefits of exercise for people with mental illness are similar to that of other chronic and complex health conditions. To overcome the lack of knowledge as a barrier to exercise prescription, GPs may consider accessing Exercise is Medicine ${ }^{\circledR}$ Australia (www.exerciseismedicine.org.au, verified 8 July 2014) 


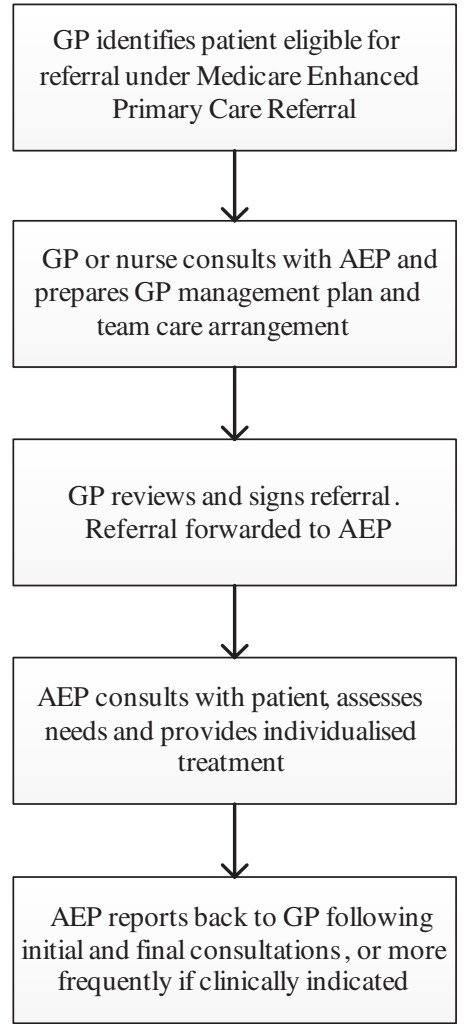

Fig. 1. Referral of patients under the Medicare Enhanced Primary Care Referral Scheme. AEP, accredited exercise physiologist.

or Exercise and Sports Science Australia (www.essa.org.au, verified 8 July 2014).

International guidelines, developed subsequent to those currently in place in Australia, recommend the inclusion of exercise as first-line treatment of patients with mental illness, particularly for those with sub-threshold or mild to moderate depression (National Institute for Health and Care Excellence 2009) or as an adjunct to pharmacotherapy for patients with mild to moderate depression (Ravindran et al. 2009). Based on recent evidence, we would consider the routine inclusion of appropriately developed, supervised and individualised exercise interventions to be of value across a range of mental illnesses, with few if any adverse events. In addition, we would consider it timely to amend the current clinical practice guideline developed for patients with depression, schizophrenia and bipolar disorder to include current best practice recommendations for exercise prescription. Lastly, and consistent with other authors (Coombes et al. 2013), we would encourage the continued uptake of the Medicare Enhanced Primary Care (MBS Item Number 10953) and other referral schemes, to provide individualised, evidencebased exercise prescription for people with mental illness. To assist GPs with understanding the referral process, a general guide is offered in Fig. 1. Alternatively, GPs may refer to the Medicare website (http://www.health.gov.au/mbsprimarycare items, verified 8 July 2014).

\section{Conflicts of interest}

None declared.

\section{References}

Abramson S, Stein J, Schaufele M, Frates E, Rogan S (2000) Personal exercise habits and counseling practices of primary care physicians: a national survey. Clinical Journal of Sport Medicine 10(1), 40-48. doi:10.1097/ 00042752-200001000-00008

Abrantes AM, Strong DR, Cohn A, Cameron AY, Greenberg BD, Mancebo MC, Brown RA (2009) Acute changes in obsessions and compulsions following moderate-intensity aerobic exercise among patients with obsessive-compulsive disorder. Journal of Anxiety Disorders 23(7), 923-927. doi:10.1016/j.janxdis.2009.06.008

AIHW (2013) 'Mental health services - in brief 2013.' (Australian Institute of Health and Welfare: Canberra)

Asmundson GJ, Fetzner MG, Deboer LB, Powers MB, Otto MW, Smits JA (2013) Let's get physical: a contemporary review of the anxiolytic effects of exercise for anxiety and its disorders. Depression and Anxiety 30(4), 362-373. doi:10.1002/da.22043

Berk M, Sarris J, Coulson CE, Jacka FN (2013) Lifestyle management of unipolar depression. Acta Psychiatrica Scandinavica 127(Suppl. 443), 38-54. doi:10.1111/acps.12124

Britt H, Miller C, Henderson J, Charles J, Valenti L, Harrison C, Bayram C, Zhang C, Pollack AJ, O'Halloran J, Pan Y (2012) 'General practice activity in Australia 2011-12. General practice series number 31.' (Sydney University Press: Sydney)

Brown RA, Abrantes AM, Strong DR, Mancebo MC, Menard J, Rasmussen SA, Greenberg BD (2007) A pilot study of moderate-intensity aerobic exercise for obsessive compulsive disorder. The Journal of Nervous and Mental Disease 195(6), 514-520. doi:10.1097/01.nmd.0000253730. $31610.6 \mathrm{c}$

Caemmerer J, Correll CU, Maayan L (2012) Acute and maintenance effects of non-pharmacologic interventions for antipsychotic associated weight gain and metabolic abnormalities: a meta-analytic comparison of randomized controlled trials. Schizophrenia Research 140(1-3), 159-168. doi:10.1016/j.schres.2012.03.017

Carpiniello B, Primavera D, Pilu A, Vaccargiu N, Pinna F (2013) Physical activity and mental disorders: a case-control study on attitudes, preferences and perceived barriers in Italy. Journal of Mental Health 22(6), 492-500. doi:10.3109/09638237.2013.815330

Coombes JS, Law J, Lancashire B, Fassett RG (2013) 'Exercise is medicine': curbing the burden of chronic disease and physical inactivity. Asia-Pacific Journal of Public Health doi:10.1177/1010539513481492

Cooney GM, Dwan K, Greig CA, Lawlor DA, Rimer J, Waugh FR, McMurdo M, Mead GE (2013) Exercise for depression. Cochrane Database of Systematic Reviews 9, CD004366.

Crews DJ, Landers DM (1987) A meta-analytic review of aerobic fitness and reactivity to psychosocial stressors. Medicine and Science in Sports and Exercise 19(5, Suppl), S114-S120.

Donaghy M, Taylor AH (2010) Should practitioners promote physical activity as a treatment for depression? Journal of the Royal College of Physicians of Edinburgh 40(2), 132-135. doi:10.4997/JRCPE. 2010.223

Ellis P (2004) Australian and New Zealand clinical practice guidelines for the treatment of depression. The Australian and New Zealand Journal of Psychiatry 38(6), 389-407. doi:10.1111/j.1440-1614.2004.01377.x

Elmslie JL, Mann JI, Silverstone JT, Williams SM, Romans SE (2001) Determinants of overweight and obesity in patients with bipolar disorder. The Journal of Clinical Psychiatry 62(6), 486-491. doi:10.4088/JCP. v62n0614

Forsyth A, Deane FP, Williams P (2009) Dietitians and exercise physiologists in primary care: lifestyle interventions for patients with depression and/or anxiety. Journal of Allied Health 38(2), e63-e68.

Frank E, Rothenberg R, Lewis C, Belodoff BF (2000) Correlates of physicians' prevention-related practices. Findings from the Women Physicians' Health Study. Archives of Family Medicine 9(4), 359-367. doi:10.1001/archfami.9.4.359 
Galletly CA, Foley DL, Waterreus A, Watts GF, Castle DJ, McGrath JJ, Mackinnon A, Morgan VA (2012) Cardiometabolic risk factors in people with psychotic disorders: the second Australian national survey of psychosis. The Australian and New Zealand Journal of Psychiatry 46(8), 753-761. doi:10.1177/0004867412453089

Garber CE, Blissmer B, Deschenes MR, Franklin BA, Lamonte MJ, Lee I-M, Nieman DC, Swain DP (2011) Quantity and quality of exercise for developing and maintaining cardiorespiratory, musculoskeletal, and neuromotor fitness in apparently healthy adults: guidance for prescribing exercise. Medicine and Science in Sports and Exercise 43(7), 1334-1359.

Glover CM, Ferron JC, Whitley R (2013) Barriers to exercise among people with severe mental illnesses. Psychiatric Rehabilitation Journal 36(1), 45-47. doi:10.1037/h0094747

Gorczynski P, Faulkner G (2010) Exercise therapy for schizophrenia Cochrane Database of Systematic Reviews (5), CD004412. doi:10.1002/ 14651858.CD004412.pub2

Happell B, Platania-Phung C, Scott D, Nankivell J (2014) Communication with colleagues: frequency of collaboration regarding physical health of consumers with mental illness. Perspectives in Psychiatric Care 50(1), 33-43. doi:10.1111/ppc. 12021

Hébert ET, Caughy MO, Shuval K (2012) Primary care providers' perceptions of physical activity counselling in a clinical setting: a systematic review. British Journal of Sports Medicine 46(9), 625-631. doi:10.1136/bjsports2011-090734

Helmich I, Latini A, Sigwalt A, Carta MG, Machado S, Velasques B, Ribeiro P, Budde H (2010) Neurobiological alterations induced by exercise and their impact on depressive disorders. Clinical Practice and Epidemiology in Mental Health 6, 115-125. doi:10.2174/1745017901006010115

Hilton MF, Scuffham PA, Vecchio N, Whiteford HA (2010) Using the interaction of mental health symptoms and treatment status to estimate lost employee productivity. The Australian and New Zealand Journal of Psychiatry 44(2), 151-161. doi:10.3109/00048670903393605

Jayakody K, Gunadasa S, Hosker C (2014) Exercise for anxiety disorders: systematic review. British Journal of Sports Medicine 48(3), 187-196. doi:10.1136/bjsports-2012-091287

Lipsky RH, Marini AM (2007) Brain-derived neurotrophic factor in neuronal survival and behavior-related plasticity. Annals of the New York Academy of Sciences 1122, 130-143. doi:10.1196/annals.1403.009

Livaudais JC, Kaplan CP, Haas JS, Perez-Stable EJ, Stewart S, Jarlais GD (2005) Lifestyle behavior counseling for women patients among a sample of California physicians. Journal of Women's Health 14(6), 485-495. doi:10.1089/jwh.2005.14.485

Malchow B, Reich-Erkelenz D, Oertel-Knochel V, Keller K, Hasan A, Schmitt A, Scheewe TW, Cahn W, Kahn RS, Falkai P (2013) The effects of physical exercise in schizophrenia and affective disorders. European Archives of Psychiatry and Clinical Neuroscience 263(6), 451-467. doi:10.1007/s00406-013-0423-2

Mammen G, Faulkner G (2013) Physical activity and the prevention of depression: a systematic review of prospective studies. American Journal of Preventive Medicine 45(5), 649-657. doi:10.1016/j.amepre.2013. 08.001

McDevitt J, Snyder M, Miller A, Wilbur J (2006) Perceptions of barriers and benefits to physical activity among outpatients in psychiatric rehabilitation. Journal of Nursing Scholarship 38(1), 50-55. doi:10.1111/ j.1547-5069.2006.00077.x

McGarry H, Hegarty K, Gunn J (2005) How do Victorian GPs manage patients with depression? Australian Family Physician 34(7), 603-606.

McGorry P, Killackey E, Lambert T, Lambert M, Jackson H, Codyre D (2005) Royal Australian and New Zealand College of Psychiatrists clinical practice guidelines for the treatment of schizophrenia and related disorders. The Australian and New Zealand Journal of Psychiatry 39(1-2), 1-30.

Mental Health Foundation (2009) 'Moving on up.'(Mental Health Foundation: London)
Morgan AJ, Parker AG, Alvarez-Jimenez M, Jorm AF (2013a) Exercise and mental health: an exercise and sports science Australia commissioned review. Journal of Exercise Physiology Online 16(4), 64-73.

Morgan AJ, Jorm AF, Reavley NJ (2013b) Beliefs of Australian health professionals about the helpfulness of interventions for mental disorders: differences between professions and change over time. The Australian and New Zealand Journal of Psychiatry 47(9), 840-848. doi:10.1177/ 0004867413490035

National Institute for Health and Care Excellence (2009) Depression: the treatment and management of depression in adults (update). NICE clinical guideline 90. Available at www.nice.org.uk/CG90 [Verified 2 November 2012]

Ravindran AV, Lam RW, Filteau MJ, Lespérance F, Kennedy SH, Parikh SV, Patten SB (2009) Canadian Network for Mood and Anxiety Treatments (CANMAT) clinical guidelines for the management of major depressive disorder in adults. V. Complementary and alternative medicine treatments. Journal of Affective Disorders 117(Suppl 1), S54-S64. doi:10.1016/j.jad.2009.06.040

Rimer J, Dwan K, Lawler DA, Greig CA, McMurdo M, Morley W, Mead GE (2012) Exercise for depression. Cochrane Database of Systematic Reviews 7, CD004366.

Robertson R, Jepson R, Shepherd A, McInnes R (2011) Recommendations by Queensland GPs to be more physically active: which patients were recommended which activities and what action they took. Australian and New Zealand Journal of Public Health 35(6), 537-542. doi:10.1111/ j.1753-6405.2011.00779.x

Rogers LQ, Gutin B, Humphries MC, Lemmon CR, Waller JL, Baranowski T, Saunders R (2006) Evaluation of internal medicine residents as exercise role models and associations with self-reported counseling behavior, confidence, and perceived success. Teaching and Learning in Medicine 18(3), 215-221. doi:10.1207/s15328015tlm1803_5

Rosenbaum S, Nguyen D, Lenehan T, Tiedemann A, van der Ploeg H, Sherrington C (2011) Exercise augmentation compared to usual care for post traumatic stress disorder: a randomised controlled trial (the REAP study: randomised exercise augmentation for PTSD). BMC Psychiatry 11(1), 115. doi:10.1186/1471-244X-11-115

Rosenbaum S, Tiedemann A, Sherrington C, Curtis J, Ward PB (2014) Physical activity interventions for people with mental illness: a systematic review and meta-analysis. The Journal of Clinical Psychiatry doi:10.4088/JCP.13r08765

Royal Australian and New Zealand College of Psychiatrists Clinical Practice Guidelines Team for Bipolar Disorder (2004) Australian and New Zealand clinical practice guidelines for the treatment of bipolar disorder. The Australian and New Zealand Journal of Psychiatry 38(5), 280-305. doi:10.1111/j.1440-1614.2004.01356.x

Searle A, Calnan M, Lewis G, Campbell J, Taylor A, Turner K (2011) Patients' views of physical activity as treatment for depression: a qualitative study. The British Journal of General Practice 61(585), 149-156. doi:10.3399/ bjgp11X567054

Stanton R (2013) Accredited exercise physiologists and the treatment of people with mental illnesses. Clinical Practice 2(2), 5-9.

Stanton R, Happell B (2014) A systematic review of the aerobic exercise program variables for people with schizophrenia. Current Sports Medicine Reports 13(4), doi:1537-890X/1304/00Y00

Stanton, R, Reaburn P (2013) Exercise prescription for people with depression. Activate September, 12-16.

Stanton R, Reaburn P (2014) Exercise and the treatment of depression: a review of the exercise program variables. Journal of Science and Medicine in Sport 17(2), 177-182.

Stanton R, Happell B, Reaburn P (2014a) The development, validation and reliability of a questionnaire to investigate the views of health professionals regarding exercise for the treatment of mental illness. Mental Health and Physical Activity. doi:10.1016/j.mhpa.2014.06.001 
Stanton R, Happell B, Reaburn P (2014b) The mental health benefits of regular physical activity, and its role in preventing future depressive episodes. Nursing: Research and Reviews 4, 45-53.

Stathopoulou G, Powers MB, Berry AC, Smits JAJ, Otto MW (2006) Exercise interventions for mental health: a quantitative and qualitative review. Clinical Psychology: Science and Practice 13(2), 179-193. doi:10.1111/ j.1468-2850.2006.00021.x

Stephenson CP, Karanges E, McGregor IS (2013) Trends in the utilisation of psychotropic medications in Australia from 2000 to 2011. The Australian and New Zealand Journal of Psychiatry 47(1), 74-87. doi:10.1177/ 0004867412466595

Sylvia LG, Ametrano RM, Nierenberg AA (2010) Exercise treatment for bipolar disorder: potential mechanisms of action mediated through increased neurogenesis and decreased allostatic load. Psychotherapy and Psychosomatics 79(2), 87-96. doi:10.1159/000270916
Toosi TD, Azizian A, Roushan N, Khasaeipur Z, Soleimanzadeh M (2009) The views of general practitioners in Iran about prevention and health promotion and related obstacles in clinical practice. Acta Medica Indonesiana 41(3), 115-120.

Tsatsoulis A, Fountoulakis S (2006) The protective role of exercise on stress system dysregulation and comorbidities. Annals of the New YorkAcademy of Sciences 1083, 196-213. doi:10.1196/annals.1367.020

Wolff E, Gaudlitz K, Lindenberger B-L, Plag J, Heinz A, Ströhle A (2011) Exercise and physical activity in mental disorders. European Archives of Psychiatry and Clinical Neuroscience 261(Suppl 2), 186-191. doi:10.1007/s00406-011-0254-y

Zschucke E, Gaudlitz K, Ströhle A (2013) Exercise and physical activity in mental disorders: clinical and experimental evidence. Journal of Preventive Medicine and Public Health 46(Suppl 1), S12-S21. doi:10.3961/jpmph.2013.46.S.S12 